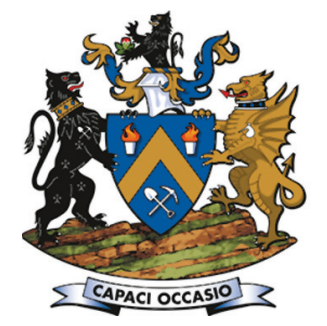

\title{
Extraction of zinc from zinc ferrites by alkaline leaching: enhancing recovery by mechanochemical reduction with metallic iron
}

\author{
by C. Zhang*, L. Zhuang*, J. Wang*, J. Bai*, and W. Yuan*
}

\section{Synopsis}

This study evaluates the efficiency of using mechanochemical reduction to assist the extraction of zinc from zinc ferrites by alkaline leaching. The transition of zinc ferrite into a metastable state after mechanochemical reduction with metallic iron contributes to the ready dissolution of zinc from the activated zinc ferrites in alkaline solution. Zinc ferrites were mechanochemically reduced under conditions of $\mathrm{Fe}: \mathrm{ZnFe}_{2} \mathrm{O}_{4}$ mole ratio of 2:1, using $5 \mathrm{~mm}$ diameter stainless steel balls as the activation medium at a mass ratio of balls to raw materials of 25:1. Subsequent leaching in 6 $\mathrm{mol} / \mathrm{L} \mathrm{NaOH}$ solution at $90^{\circ} \mathrm{C}$ resulted in more than $70 \% \mathrm{Zn}$ extraction. These results may be used to further develop a hydrometallurgical process for recovering zinc from zinc ferrites in alkaline solution.

\section{Keywords}

zinc ferrite, mechanochemical reduction, metallic iron, alkaline leaching.

\section{Introduction}

Zinc is an important nonferrous metal required for various applications in batteries, solder, dielectric materials, and piezoelectric materials. High-grade, easily concentrated ores are becoming scarcer: to meet world demands for zinc, it is necessary to develop economical and environmentally safe metallurgical technologies that use secondary materials such as leach residues of roasted zinc concentrates and electric arc furnace dusts. The zinc in the majority of these wastes occurs in the form of zinc ferrite (franklinite, $\mathrm{ZnFe}_{2} \mathrm{O}_{4}$ ), which is very stable and insoluble in most acidic and alkaline solutions (Langová and Matýsek, 2009; Youcai and Stanforth, 2000).

Several pyrometallurgical and hydrometallurgical processes (Jankovi et al., 2014; Langová and Matýsek, 2010; Morcali et al., 2012; Shawabkeh, 2010) have been proposed for the treatment of zinc ferrites.

Pyrometallurgical methods are costly owing to high energy consumption and their emissions of toxic gases are considered an environmental problem; hydrometallurgical methods are preferred for process economy and environmental reasons (Copur et al., 2004).

Because of the need to eliminate elements such as $\mathrm{Fe}, \mathrm{Cd}$, $\mathrm{Ni}$, and $\mathrm{Co}$ from the leachate and the high acid consumption incurred for the digestion of iron oxides, industrial-scale utilization of acidic leaching processes has been impeded. Only $\mathrm{Zn}$ and $\mathrm{Pb}$ dissolve effectively in caustic alkaline solution, so alkaline processes are often chosen to leach $\mathrm{Zn}$ and $\mathrm{Pb}$ selectively from $\mathrm{Zn}$-bearing dusts and secondary resources (Youcai and Stanforth, 2001). However, it is difficult to extract zinc from zinc ferrite by $\mathrm{NaOH}$ solution under atmospheric pressure: the maximum reported extraction of zinc from decomposed zinc ferrite was only about $9 \%$, after leaching in $10 \mathrm{M}$ $\mathrm{NaOH}$ solution for 3 hours at $93^{\circ} \mathrm{C}$ (Xia and Pickles, 1999).

Youcai and Stanforth (2000) showed that the zinc ferrite structure could be broken by fusing it with sodium hydroxide: the dust was hydrolyzed in water and then fused with caustic soda at $350^{\circ} \mathrm{C}$, following which $95 \%$ of the zinc was leached. However, in addition to leachable Zn, elements such as Fe and Ca may also react with sodium hydroxide during fusion of the zinc ferrite, resulting in high consumptions of this reagent.

Mechanical activation of minerals nowadays represents an important contribution to different fields of solids processing technology. Mechanical activation comprises high-energy ball milling, during which the particles undergo repeated fracturing and cold welding during collisions either between balls or between a ball and the inner wall of the mill (Gilman and Benjamin, 2009). In extractive metallurgy, activation by high-energy milling is reported to decrease the reaction temperature in pyrometallurgical processes and

* Shanghai Cooperative Centre for WEEE Recycling, Shanghai Polytechnic University, Shanghai, China.

(c) The Southern African Institute of Mining and Metallurgy, 2016. ISSN 2225-6253. Paper received Sep. 2014; revised paper received Jan. 2016. 


\section{Extraction of zinc from zinc ferrites by alkaline leaching}

increase the leaching kinetics of several sulphide and oxide minerals in (Baláž and Ebert, 1991; Ping et al., 2011; Tiechui et al., 2010; Zhao et al., 2009).

The aim of this study was to investigate the effect of using mechanochemical reduction with metallic iron on the extraction of zinc from zinc ferrites in alkaline solution.

\section{Experimental}

\section{Materials}

The zinc ferrites were provided by Nubiola Pigments Co., Ltd (Shanghai, China). X-ray diffraction (XRD) analysis confirmed their high purity (

\section{Mechanical activation and mechanochemical reduction of zinc ferrites}

Mechanical activation or mechanochemical reduction of zinc ferrite was carried out using a planetary ball mill (QM-QX04, Nanjing NanDa Instrument Plant, China). Stainless steel balls with diameters between $1 \mathrm{~mm}$ and $5 \mathrm{~mm}$ were used as the grinding medium. The mass ratio of balls to ferrite was 25:1.

\section{Alkaline leaching}

Leaching of mechanically activated or mechanochemically reduced zinc ferrite was carried out in a flask placed on a thermostatically controlled magnetic stirrer. Zinc ferrite was added to $250 \mathrm{~mL}$ of $\mathrm{NaOH}$ solution and then leached at constant temperature. The volume was kept constant by adding water. The leach residue was thoroughly washed with $\mathrm{NaOH}$ solution and water and then dried. The zinc in solution was analysed by inductively coupled plasma atomic emission spectroscopy (ICP-AES). The percentage of zinc leached was calculated according to Equation [1]:

$$
\text { Zinc extraction }(\%)=\left[\left(C_{1} \times V_{1}\right) /\left(W_{1} \times C_{2}\right)\right] \times 100 \%
$$

where $W_{1}(\mathrm{~g})$ is the mass of zinc ferrites; $V_{1}(\mathrm{~L})$ is the volume of the leach solution; $C_{1}(\mathrm{~g} / \mathrm{L})$ is the zinc concentration in the leach solution; and $C_{2}(\%)$ is the zinc content in the zinc ferrites.

\section{Results and discussion}

Direct alkaline leaching of $\mathrm{ZnFe}_{2} \mathrm{O}_{4}$

Zinc ferrite was leached in $6 \mathrm{M} \mathrm{NaOH}$ at $90^{\circ} \mathrm{C}$. Less than $2 \%$

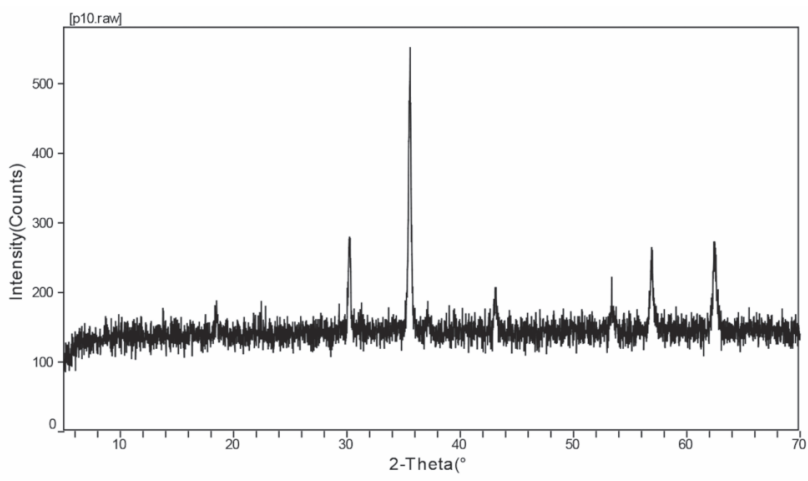

Figure 1-X-ray diffraction pattern of the zinc ferrite raw material of the total zinc was released from the zinc ferrite (Figure 2), indicating that direct alkaline leaching is not an effective means of extracting zinc from this source.

\section{Alkaline leaching after mechanical activation}

The results for the leaching of zinc ferrite that was mechanically activated in a planetary ball mill are shown in Figure 3. Compared with the non-activated sample, the zinc extraction increased slightly: about $13 \%$ of the contained zinc was released after 4 hours of mechanical activation.

\section{Alkaline leaching after mechanochemical reduction with metallic iron}

Because the zinc was not extracted from zinc ferrites by alkaline leaching after mechanical activation, mechanochemical reduction with metallic iron was tested.

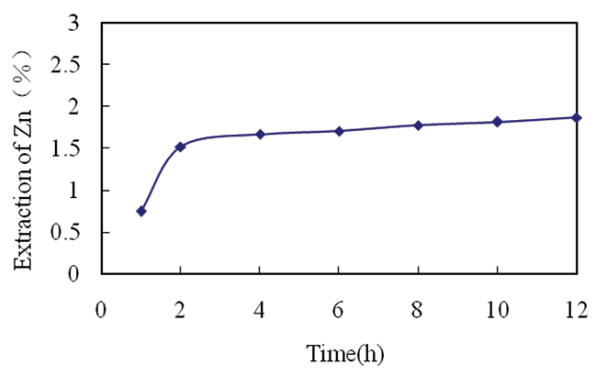

Figure 2-Direct alkaline leaching of $\mathrm{ZnFe}_{2} \mathrm{O}_{4}$ (temperature $90^{\circ} \mathrm{C}$; $\mathrm{NaOH}$ concentration $6 \mathrm{M}$; solids density (v/w) 25)

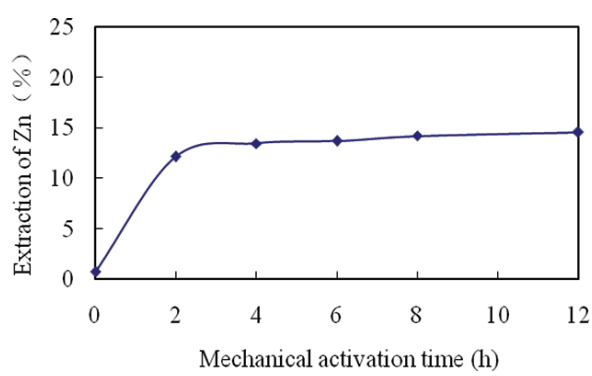

Figure 3-Effect of mechanical activation time on zinc extraction from $\mathrm{ZnFe}_{2} \mathrm{O}_{4}$

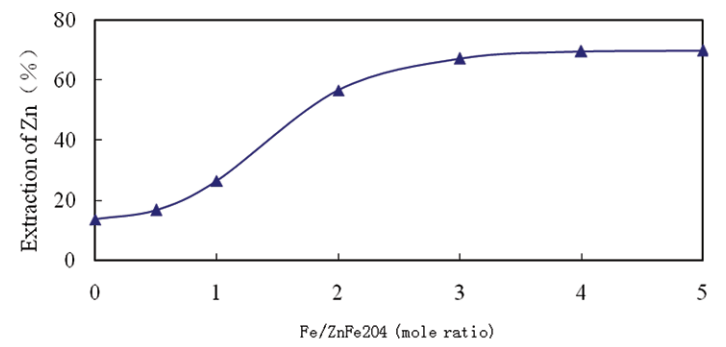

Figure 4-Effect of Fe: $\mathrm{ZnFe}_{2} \mathrm{O}_{4}$ ratio during mechanochemical reduction on zinc extraction during subsequent alkaline leaching 


\section{Extraction of zinc from zinc ferrites by alkaline leaching}

\section{Effect of $\mathrm{Fe}: \mathrm{ZnFe}_{2} \mathrm{O}_{4}$ ratio}

The zinc ferrites were leached in $6 \mathrm{M} \mathrm{NaOH}$ at $90^{\circ} \mathrm{C}$ after 4 hours of mechanochemical reduction at different $\mathrm{Fe}: \mathrm{ZnFe}_{2} \mathrm{O}_{4}$ ratios. The leaching efficiency increased considerably as the proportion of metallic iron increased (Figure 4). Maximum leaching efficiency was obtained when the $\mathrm{Fe}: \mathrm{ZnFe}_{2} \mathrm{O}_{4}$ mole ratio exceeded 2:1.

XRD patterns of the $\mathrm{ZnFe}_{2} \mathrm{O}_{4}$ after grinding with $\mathrm{Fe}$ at different molar ratios for 6 hours are shown in Figure 5. The intensities of the main diffraction peaks of $\mathrm{ZnFe}_{2} \mathrm{O}_{4}$ tended to decrease as the $\mathrm{Fe}: \mathrm{ZnFe}_{2} \mathrm{O}_{4}$ mole ratio increased. It is reported that mechanically induced structural changes in zinc ferrite cause its gradual transition into a metastable state (Boldyrev, 2006; Tkacova et al., 1996) as a result of mechanically induced inversion and deformation of its octahedral geometry, which can be enhanced by the addition of metallic iron.

The chemical bonding environments of Fe2p, Zn2p in zinc ferrite after mechanochemical reduction were analysed by XPS, and the results are shown in Figure 6. As shown in Figure $6 \mathrm{~A}$, it was found that the binding energy for Fe 2p3/2 in zinc ferrite is $710.15 \mathrm{eV}$, which matches well with the $\mathrm{Fe}^{3+}$ components in $\mathrm{ZnFe}_{2} \mathrm{O}_{4}$ (Pan et al., 2011; Bear et al., 2001). After grinding with $\mathrm{Fe}$, the peaks shift to lower positions by about $0.18-0.19 \mathrm{eV}$, which indicates that the content of $\mathrm{Fe}^{2+}$ is increased according to the reduction of $\mathrm{Fe}^{3+}$ to $\mathrm{Fe}^{2+}$ (Hou, 2014).

The zinc spectra of mechanochemically reduced zinc ferrite in Figure $6 \mathrm{~B}$ with the binding energies of $\mathrm{Zn} 2 \mathrm{p}_{3 / 2}$ and $\mathrm{Zn} 2 \mathrm{p}_{1 / 2}$ are measured as $1021.47 \mathrm{eV}$ and $1044.58 \mathrm{eV}$, which is consistent with the XPS results for the standard $\mathrm{ZnFe}_{2} \mathrm{O}_{4}$ materials (Tahir and Upul Wijayantha, 2010.). The peak positions of $\mathrm{Zn} 2 \mathrm{p}_{3 / 2}$ and $\mathrm{Zn} 2 \mathrm{p}_{1 / 2}$ shift to the lower binding energy side after mechanochemical reduction with $\mathrm{Fe}$, which is evidence for the decomposition of zinc ferrite and formation of $\mathrm{Zn} x \mathrm{Fe}_{3}-\mathrm{xO}_{4}$ solid solution (Hou , 2014; Kaneko, 2004).

\section{Effect of mechanochemical reduction time}

The effect of mechanochemical reduction time on zinc extraction is shown in Figure 7. As expected, the rate of zinc leaching increased with an increase in reduction time. Maximum extraction was achieved after about 6 hours.

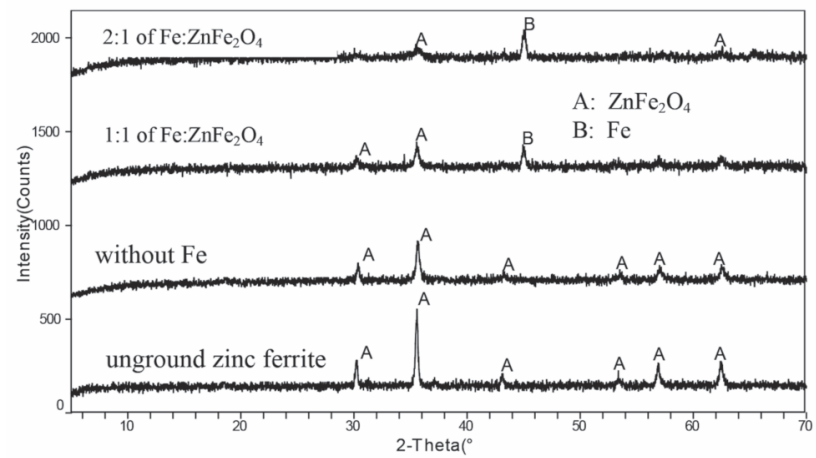

Figure 5-X-ray diffraction patterns of zinc ferrite after grinding with $\mathrm{Fe}$ at different molar ratios for 6 hours

\section{Effect of milling rotational speed}

In planetary ball milling, energy is supplied by the rotation of the mill. Different rotational speeds therefore supply different energies. This can significantly affect the reaction rate of the mechanochemical reduction.

The effect of rotational speed of the mill on zinc extraction is shown in Figure 8. Zinc extraction increased with increasing rotational speed: $70.38 \%$ extraction was achieved at speeds greater than $500 \mathrm{r} / \mathrm{min}$.

\section{Conclusions}

Zinc in zinc ferrites can be leached in $\mathrm{NaOH}$ solution after mechanochemical reduction with metallic iron. A mechanically induced inversion and deformation in the octahedral geometry leads to the transition of zinc ferrite into a metastable state. Over $70 \%$ of the contained zinc was extracted from mechanochemically reduced zinc ferrites, compared with less than $2 \%$ extraction for alkaline leaching
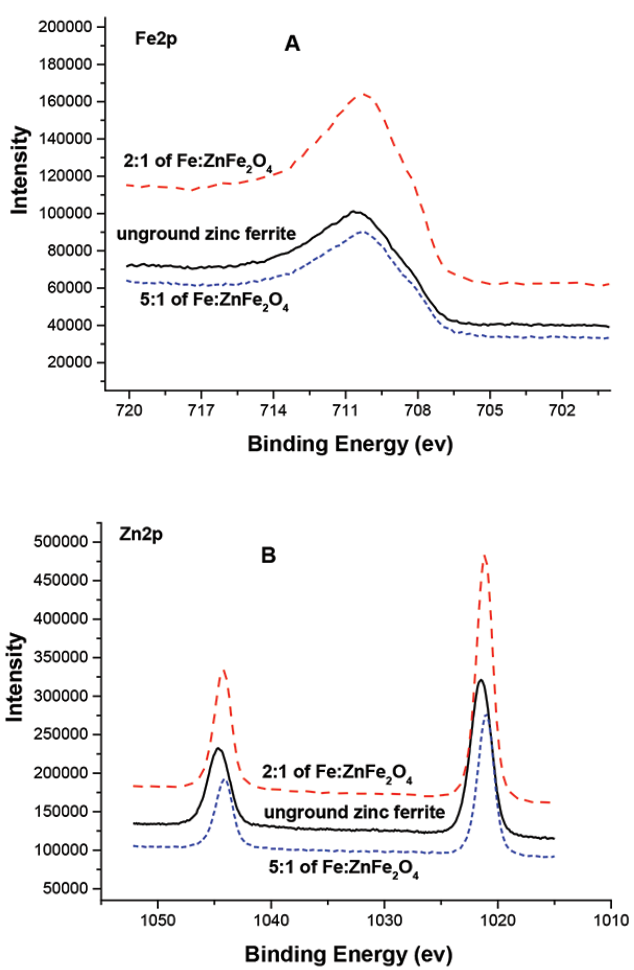

Figure 6-Fe2p, Zn2p spectra of raw and mechanochemically reduced samples

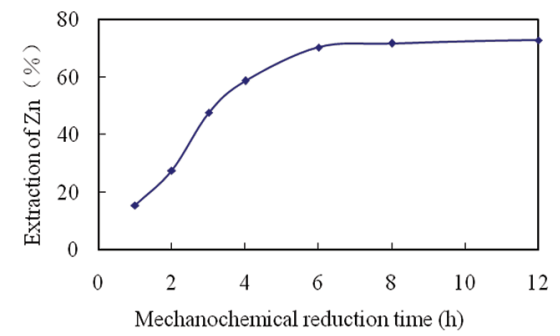

Figure 7-Effect of mechanochemical reduction time on zinc extraction from $\mathrm{ZnFe}_{2} \mathrm{O}_{4}$ 


\section{Extraction of zinc from zinc ferrites by alkaline leaching}

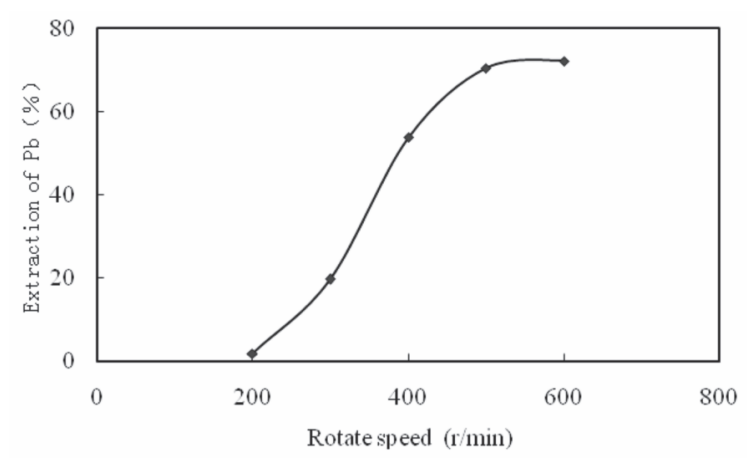

Figure 8-Effect of rotation speed on zinc extraction

of non-activated samples and 13\% extraction for alkaline leaching of activated samples following 2 hours of planetary ball milling. The proposed alkaline leaching processes to recover $\mathrm{Zn}$ from zinc ferrite-bearing dusts and secondary resources can therefore be enhanced by mechanochemical reduction with metallic iron.

\section{Acknowledgements}

The authors gratefully acknowledge financial support from the National Natural Science Funds of China (No. 51008189 and No. 51474146) and the Shanghai Municipal Natural Science Funds (No. 14ZR1416900).

\section{References}

BALÁž, P. and EBERT, I. 1991. Oxidative leaching of mechanically activated sphalerite. Hydrometallurgy, vol. 279. pp. 141-150.

Bear, S., Prince, A.A.M., Velmurugan, S., Raghavan, P.S., Gopalan, R., Panneerselvam, G., and Narasimhan, S.V. 2001. Formation of zinc ferrite by solid-state reaction and its characterization by XRD and XPS. Journal of Materials Science, vol. 36. pp.5379-5384.

BoLDYREV, V.V. 2006. Mechanochemistry and mechanical activation of solids. Russian Chemical Reviews, vol. 75, no. 3. pp.177-189.

Copur, M., Ozmetin, C., Ozmetin, E., and KocaKerim, M. 2004. Optimization study of the leaching of roasted zinc sulphide concentrate with sulphuric acid solutions. Chemical Engineering and Processing, vol. 43. pp. 1007-1014.

Gilman, P.S. and Benjamin, J.S. 2009. Mechanical alloying. Annual Review of Materials Science, vol.13. pp. 279-300.

Hou, D.-K., Peng, B., Chai L.-Y., Peng, N., and Yan, H. 2014. Selective reduction mechanism of zinc ferrite. Chinese Journal of Nonferrous Metals, vol. 24, no. 10. pp. 2634-2641.

Janković, B., Stopić, S., Güven, A., and Friedrich, B. 2014. Kinetic modeling of thermal decomposition of zinc ferrite from neutral leach residues based on stochastic geometric model. Journal of Magnetism and Magnetic Materials, vol. 358-359. pp. 105-118.
Kaneko, H., Gokon, N., Aiuchi, K., Tamaura, Y., Kodama, T., Lovegrove, K., and Luzzi, A. 2004. Decomposition of Zn-ferrite for $\mathrm{O}_{2}$ generation by concentrated solar radiation. Solar Energy, vol. 76, no.1. pp. 317-322.

LANGovÁ, Š., LEŠKo, J., and MATÝSEK, D. 2009. Selective leaching of zinc from zinc ferrite with hydrochloric acid. Hydrometallurgy, vol. 95. pp. 179-182.

Morcali, M.H., Yucel, O., Aydin, A., and Derin, B. 2012. Carbothermic reduction of electric arc furnace dust and calcinations of Waelz oxide by semi-pilot scale rotary furnace. Journal of Mining and Metallurgy Section $B$ Metallurgy, vol. 48, no. 2. pp.173-184.

Pan, F., Guo, Y., Cheng, F.-F., FA, T., and Yao, S.-D. 2011. Synthesis of $\mathrm{ZnFe}_{2} \mathrm{O}_{4}$ nanomagnets by $\mathrm{Fe}$-ion implantation into $\mathrm{ZnO}$ and postannealing. Chinese Physics B, vol. 20, no. 12. p. 127501-1-127501-6.

LANGová, S. and MATÝseK, D. 2010. Zinc recovery from steel-making wastes by acid pressure leaching and hematite precipitation. Hydrometallurgy, vol. 101. pp. 171-173

SHАWАВКЕН, R.A. 2010. Hydrometallurgical extraction of zinc from Jordanian electric arc furnace dust. Hydrometallurgy, vol. 104. pp. 61-65.

TAhIR, A.A. and UpUl WiJAYAntha, K.G. 2010. Photoelectrochemical water splitting at nanostructured $\mathrm{ZnFe}_{2} \mathrm{O}_{4}$ electrodes. Journal of Photochemistry and Photobiology A: Chemistry, vol. 216, no. 2-3. pp. 119-125.

TAN, P., HuI,-P., and ZHANG, L. 2011. Effects of mechanical activation and oxidation-reduction on hydrochloric acid leaching of Panxi ilmenite concentration. Transactions of Nonferrous Metals Society of China, vol. 21. pp. 1414-1421.

TKacova, K., SePelaK, V., and Stevulova, N. 1996. Structure-reactivity study of mechanically activated zinc ferrite. Journal of Solid State Chemistry, vol. 123. pp. 100-108

XIA, D.K. and PICKLES, C.A. 1999. Kinetics of zinc ferrite leaching in caustic media in the deceleratory period. Minerals Engineering, vol. 12, no. 6. pp. 693-700.

YouCAI, Z. and STANFoRTH, R. 2000. Integrated hydrometallurgical process for production of zinc from electric arc furnace dust in alkaline medium. Journal of Hazardous Materials, vol. B80. pp. 223-240.

YuAn, T., CAO, Q., and LI, J. 2010. Effects of mechanical activation on physicochemical properties and alkaline leaching of hemimorphite. Hydrometallurgy, vol. 104. pp.136-141.

Zha, Y. and Stanforth, R. 2001. Selective separation of lead from alkaline zinc solution by sulfide precipitation. Separation Science and Technology, vol. 36 , no. 11. pp. 2561-2570.

Zhao, Z., Long, S., Chen, A., Huo, G., Li, H., Xijun J., and Chen, X. 2009. Mechanochemical leaching of refractory zinc silicate (hemimorphite) in alkaline solution. Hydrometallurgy, vol. 99. pp. 255-258. 